\section{Infographic. Make physical activity a part of daily life at all stages in life}

\author{
Ann B Gates, ${ }^{1}$ AD Murray ${ }^{2}$
}

\section{INTRODUCTION}

Make physical activity a part of daily life during all stages of life. That is the clear message from the World Health Organisation in this infographic. ${ }^{1}$

Regular physical activity is a fundamental means of improving people and population's physical and mental health.

${ }^{1}$ Exercise Works! Derby UK; ${ }^{2}$ Sport and Exercise, University of Edinburgh, Edinburgh, UK

Correspondence to Andrew Murray, Sports and Exercise Medicine consultant, Physical Activity for Health Research Centre, 2.33 St Leonard's Land, University of Edinburgh, Edinburgh, UK; docandrewmurray@googlemail.com
It reduces the risks of many noncommunicable (NCD) diseases and benefits society by increasing social interaction and community engagement. Physical activity is not just a public health issue; it also promotes the well-being of communities, the protection of the environment, and is an investment in future generations.

Physical activity includes all activities which involve bodily movement and can be accrued through:

- active travel

- work and occupation

- leisure and recreation

- housework and gardening

This infographic demonstrates that regular physical activity throughout the life-course enables people to live better and longer lives. It inspires people to "make physical activity a part of daily life, during all stages of life".

What a great call to action!

Correction notice This paper has been amended since it was published Online First. The first author's full name is now included and we have added a weblink to the World Health Organization.

Twitter Follow Ann Gates at @exerciseworks, Andrew Murray at @docandrewmurray

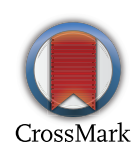

To cite Gates AB, Murray AD. Br I Sports Med 2017; 51:825-826.

Published Online First 29 July 2016

Br J Sports Med 2017;51:825-826. doi:10.1136/bjsports-2016-096643 
Make physical activity a part of daily life during all stages of life
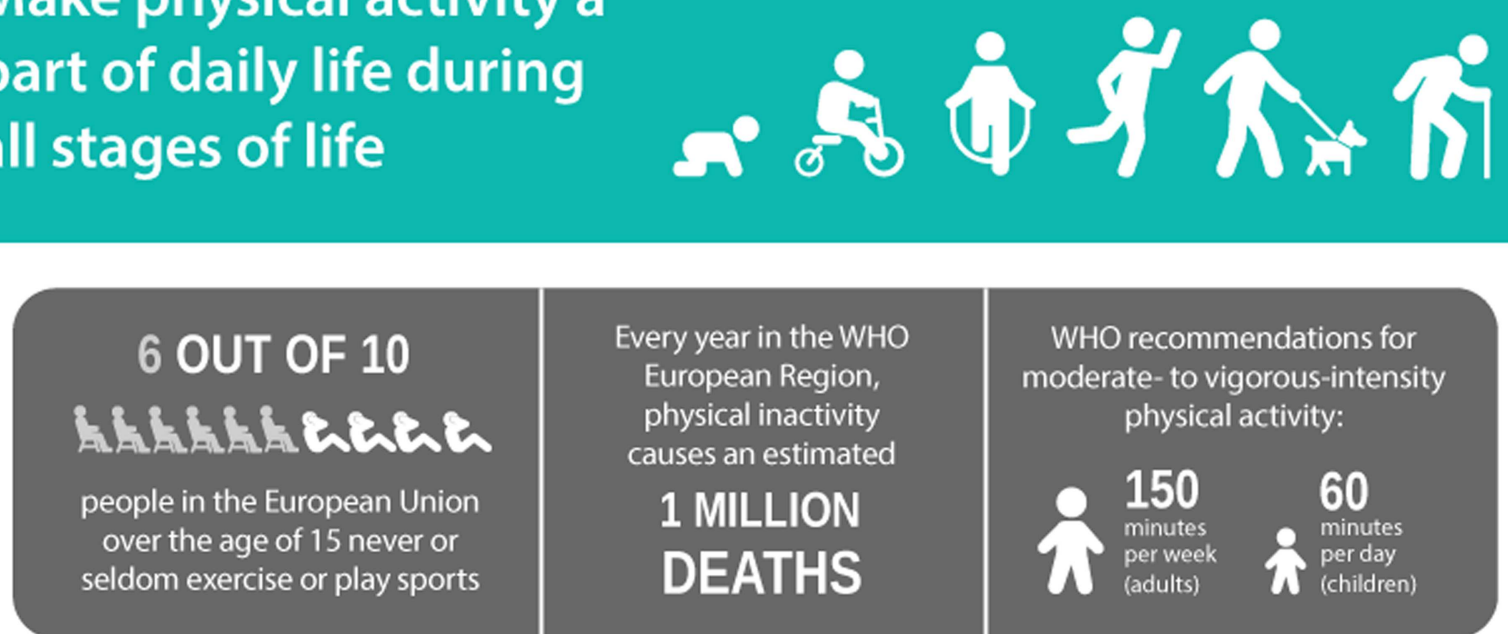

Every year in the WHO European Region, physical inactivity causes an estimated 1 MILLION DEATHS

\section{$\underline{\underline{G}}$}

$c$

$\frac{\infty}{8}$

के

용

$\stackrel{\vec{F}}{\vec{B}}$

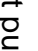
physical activity:

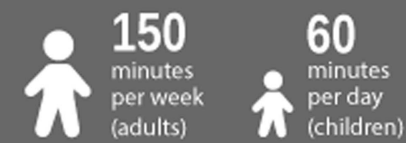

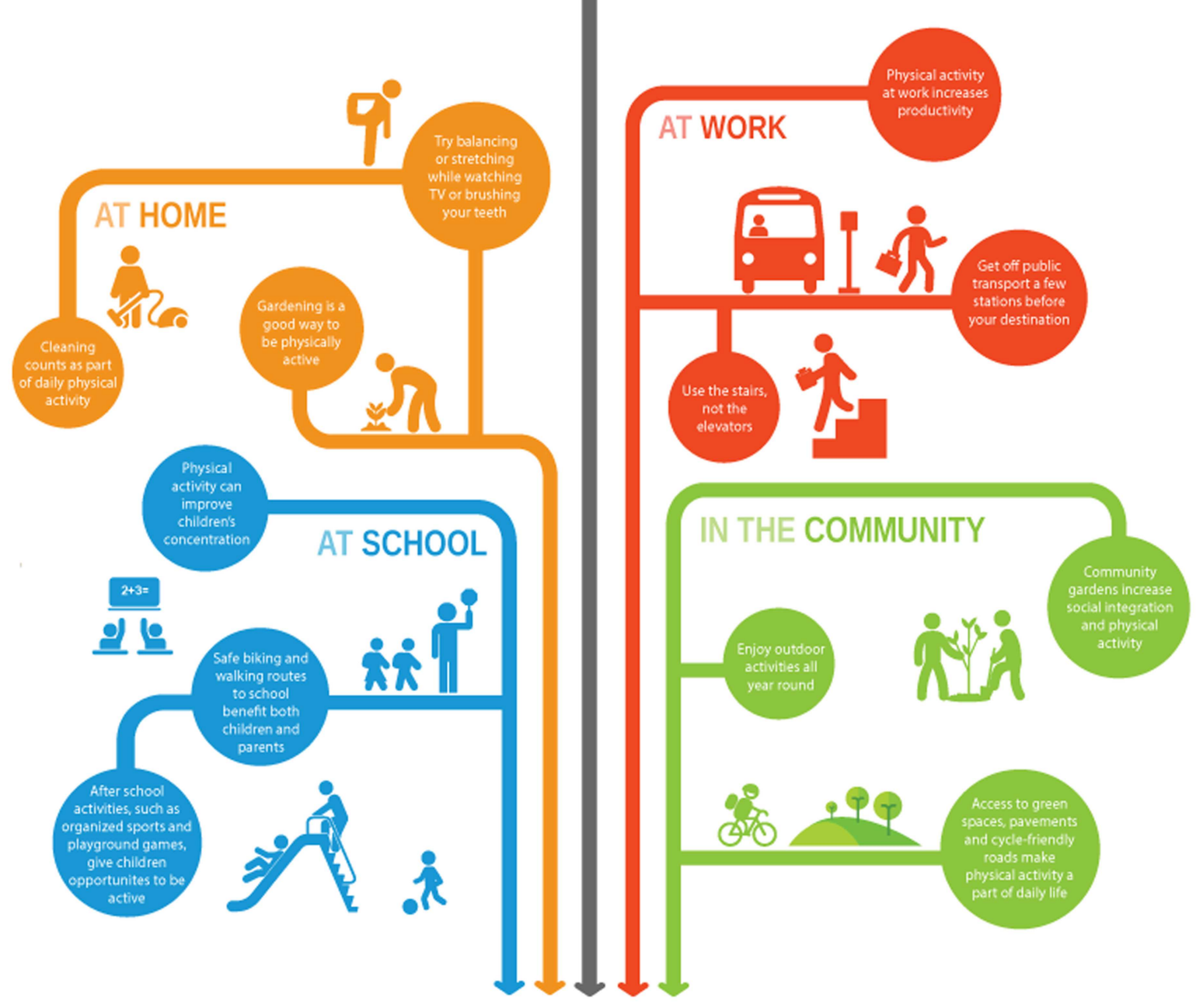

REGULAR PHYSICAL ACTIVITY THROUGHOUT THE LIFE-COURSE ENABLES PEOPLE TO LIVE BETTER AND LONGER LIVES 